\title{
Non-Infectious Complications of Peritoneal Dialysis in Senegal
}

\author{
Ahmed Tall Lemrabott1 ${ }^{*}$, Maria Faye1, Moustapha Faye1, Abdoul Hassane Sanlé Traoré1, \\ Mouhamadou Moustapha Cissé2, Khodia Fall1, Yaya Kane ${ }^{3}$, Zeinabou Maiga Moussa Tondi', \\ Mansour Mbengue1, Bacary Ba1, Niakhalee Keita1', Seynabou Diagne1, Abdou Niang1, \\ Boucar Diouf ${ }^{1}$, El Hadji Fary Ka ${ }^{1}$
}

\author{
${ }^{1}$ Department of Nephrology, Aristide Le Dantec University Hospital, Dakar, Senegal \\ ${ }^{2}$ Department of Nephrology, Thies University, Thies, Senegal \\ ${ }^{3}$ Internal Medicine and Nephrology, Assane Seck University, Ziguinchor, Senegal \\ ${ }^{4}$ Department of Nephrology and Haemodialysis, Faculty of Sciences and Health of the Abdou Moumouni \\ University of Niamey, Niamey, Niger \\ Email: *ahmedtall35@hotmail.com
}

How to cite this paper: Lemrabott, A.T., Faye, M., Faye, M., Traoré, A.H.S., Cissé, M.M., Fall, K., Kane, Y., Tondi, Z.M.M., Mbengue, M., Ba, B., Keita, N., Diagne, S., Niang, A., Diouf, B. and Ka, El H.F. (2020) Non-Infectious Complications of Peritoneal Dialysis in Senegal. Open Journal of Nephrology, 10, 43-49.

https://doi.org/10.4236/ojneph.2020.101006

Received: February 11, 2020

Accepted: March 9, 2020

Published: March 12, 2020

Copyright $\odot 2020$ by author(s) and Scientific Research Publishing Inc. This work is licensed under the Creative Commons Attribution International License (CC BY 4.0).

http://creativecommons.org/licenses/by/4.0/ (c) (i) Open Access

\begin{abstract}
Introduction: Senegal has pioneered the implementation of peritoneal dialysis (PD) in West Africa, practicing it since 2004. Non-infectious complications are a significant cause of failure of this technique and the transfer of patients to haemodialysis. The aim of this study was to determine the prevalence and the different types of non-infectious complications in our context. Patients and Methods: This was a 5-year, descriptive, retrospective study of patients on chronic peritoneal dialysis for more than 3 months. Results: During the study period, 75 patients were included. The prevalence of non-infectious complications was $88 \%$, including $45.3 \%$ mechanical complications and $76 \%$ metabolic complications. Catheter migration was the most common mechanical complication (55.9\%), followed by catheter blockage (23.5\%). Metabolic complications were dominated by hypoalbuminemia (76.3\%). Dyslipidaemia and hypokalaemia affected more than $50 \%$ of patients, occurring in $59.3 \%$ and $56.9 \%$ of cases, respectively. Conclusion: In our study, non-infectious complications related to PD were frequent and varied. They remain a significant cause of technical failure. Mechanical complications are often the cause of permanent transfer to haemodialysis.
\end{abstract}

\section{Keywords}

Peritoneal Dialysis, Non-Infectious Complications, Catheter Migration, Hypoalbuminemia, Hypokalaemia 


\section{Introduction}

Peritoneal dialysis (PD) is the least used extrarenal cleansing technique; it only involves $11 \%$ of dialysis patients, with great variability between the different regions; despite the definite advantages, both in terms of the autonomy it provides and its accessibility to the most fragile patients [1].

Non-infectious complications are secondary to the implementation of the DP catheter in the peritoneal cavity, the increase in intra-abdominal pressure by the dialysate, and the metabolic effects of absorption of glucose and its by-products. Mechanical complications are frequent and represent around $20 \%$ of hemodialysis transfers. Prevention, early recognition and proper management of these complications are paramount due to patient-related morbidity and technique failure [2].

In Senegal, PD has been practiced since 2004. It involves around $12 \%$ of patients in extrarenal treatment. This low level of patient management by this technique is partly linked to the occurrence of complications. Besides the most frequent and serious infectious complications, non-infectious complications represent a non-negligible cause of failure ( $8 \%$ to $20 \%$ transition to haemodialysis) [3] [4]. These complications are mechanical and metabolic.

Since the implementation of this technique in Senegal, no study has focused specifically on non-infectious complications of PD. Therefore, we conducted this study, which aims to determine the prevalence and the types of non-infectious complications in our PD unit.

\section{Patients and Methods}

This is a retrospective and descriptive study conducted in the peritoneal dialysis unit of the nephrology, dialysis and renal transplant department of the Aristide Le Dantec teaching hospital in Dakar (Senegal), over a period of 5 years, from 1 January 2013 to 31 December 2017. We included all patients who underwent peritoneal dialysis treatment for at least 3 months for chronic kidney disease at stage 5D. PD patients for acute renal failure and patients on vacation in Senegal were not included.

Data were collected from patients' medical records. For each patient included, the following parameters were studied: age, sex, causal nephropathy, PD procedures and clinical and biological parameters, notably albuminemia, glycemia, total cholesterolaemia, HDL-cholesterolaemia, LDL-cholesterolaemia and triglyceridaemia, were collected.

For each type of mechanical and metabolic non-infectious complication, we collected the average age of patients and the average time to onset compared with the start of PD.

In terms of equipment, the Tenckhoff double-sleeve catheter was used on all patients. The catheter was placed by the surgical method by a non-dedicated urological surgeon. The techniques used were continuous ambulatory peritoneal dialysis (CAPD) and continuous cycling peritoneal dialysis (CCPD). For CAPD, 
a BAXTER ${ }^{\circledast}$ type disconnectable double pocket system was used. Glucose bags (physioneal $^{\circledR}$ ) of $1.36 \%, 2.27 \%$ and $3.86 \%$, icodextrin $\left(\right.$ Extraneal $\left.^{\circledR}\right)$ and amino acids $\left(\right.$ Nutrineal $\left.{ }^{\circledR}\right)$ were used.

Mechanical complications were defined by the appearance of complications due to the catheter after its insertion and/or due to the presence of intraperitoneal fluid. Metabolic complications were those attributable to PD (hypokalaemia, hyperglycaemia, hypoalbuminemia, dyslipidaemia).

The collected data were analysed by using IBM SPSS Statistics version 25 software. Qualitative variables are presented as a percentage, and quantitative variables are presented as an average plus or minus the standard deviation or with a minimum and a maximum.

\section{Results}

\section{- Study population}

During the study period, 84 patients benefited from the placement of a peritoneal dialysis catheter. Nine patients were not included due to unusable medical records. The study thus involved 75 patients, of whom 57 were on CAPD and 18 were on CCPD. There were 30 men (40\%) and 45 women (60\%), for a sex ratio of 0.66 . The mean patient age was $48.6 \pm 14.4$ years.

Seventy-one patients (94.7\%) were hypertensive, and 7 patients (9.3\%) were diabetic. The first causative agent of nephropathy was nephroangiosclerosis in 31 patients (41.3\%) (Table 1$)$.

Sixty-six patients $(88 \%)$ presented at least one non-infectious complication, including 23 men (34.8\%) and 43 women (65.2\%). The mean age was $50.1 \pm 13.9$ years. The mean duration of PD was $18 \pm 11$ months, with extremes of 3 and 56 months.

\section{- Mechanical complications}

The number of patients who presented with at least one mechanical complication was 34 , i.e. a prevalence of $45.3 \%$. The mean age was $47.7 \pm 12.3$ years. Table 2 represents the prevalence of the various mechanical complications and their average time of onset compared with the beginning of PD.

\section{- Metabolic complications}

The number of patients who presented at least one metabolic complication was $57 \%$ or $76 \%$ of the patients included. The mean age was $50.8 \pm 13.8$ years. The distribution of patients according to metabolic complications is shown in Table 3.

\section{Discussion}

Mechanical complications in PD are frequent and remain highly variable depending on the region of the world, experience of services, type of catheter and insertion technique used.

The prevalence of mechanical complications in our study (45.3\%) was slightly higher than that of the Moroccan and Pakistani studies, where the prevalence was $37 \%$ and $40 \%$, respectively [5] [6]. 
Table 1. Distribution of patients by cause of nephropathy.

\begin{tabular}{lcc}
\hline \multicolumn{1}{c}{ Cause of nephropathy } & Number & Percentage \\
\hline Hypertensive nephropathy & 31 & $41.3 \%$ \\
Chronic glomerulonephritis & 18 & $24 \%$ \\
Chronic kidney disease of unknown aetiology & 14 & $18.7 \%$ \\
Diabetic nephropathy & 7 & $9.3 \%$ \\
Autosomal dominant polycystic kidney disease & 3 & $4 \%$ \\
Chronic tubulointerstitial nephritis & 1 & $1.3 \%$ \\
Cortical necrosis & 1 & $1.3 \%$ \\
\hline
\end{tabular}

Table 2. Mechanical complications and their average time of onset.

\begin{tabular}{cccc}
\hline $\begin{array}{c}\text { Types of mechanical } \\
\text { complications }\end{array}$ & Number & $\begin{array}{c}\text { Percentage in } \\
\text { population of PD }\end{array}$ & $\begin{array}{c}\text { Average time of onset } \\
\text { (months) }\end{array}$ \\
\hline Catheter migration & 19 & $25.3 \%$ & $5.8 \pm 8.7$ \\
Catheter obstruction & 8 & $10.7 \%$ & $11.7 \pm 11.4$ \\
Accidental cutting & 6 & $8 \%$ & $13.5 \pm 8.9$ \\
Bend in the catheter & 6 & $8 \%$ & $9.2 \pm 10$ \\
Hernias & 4 & $5.3 \%$ & $10.8 \pm 4.9$ \\
Bleeding of abdominal walls & 2 & $2.7 \%$ & 0.6 \\
Hemoperitoneum & 2 & $2.7 \%$ & $7.5 \pm 7.7$ \\
Intestinal perforation & 1 & $1.3 \%$ & 6 \\
\hline
\end{tabular}

Table 3. Metabolic complications and their time of onset.

\begin{tabular}{cccc}
\hline $\begin{array}{c}\text { Types of mechanical } \\
\text { complications }\end{array}$ & Number & $\begin{array}{c}\text { Percentage in } \\
\text { population of PD }\end{array}$ & $\begin{array}{c}\text { Average time of } \\
\text { onset (months) }\end{array}$ \\
\hline $\begin{array}{c}\text { Hypoalbuminemia } \\
\text { Dyslipidaemia }\end{array}$ & 29 & $76.3 \%$ & $8.7 \pm 10.7$ \\
Hypokalaemia & 16 & $59.3 \%$ & $19.8 \pm 15.9$ \\
Hyperglycaemia & 42 & $56 \%$ & $7.1 \pm 9.3$ \\
\hline
\end{tabular}

In our series, catheter migration was found in $25.3 \%$ of cases and represented the most frequent mechanical complication (55.9\% of complications). These results are corroborated by Miftah et al. [4], as well as Flayou et al. in Morocco [7], who noted a respective prevalence of $24.2 \%$ (or $65.2 \%$ of complications) and $23.6 \%$ (or $36.8 \%$ of complications).

Blockage of the catheter was noted in $10.7 \%$ of our patients. Miftah et al. [5] reported a higher prevalence at $13 \%$. Huraib et al. in Saudi Arabia [8] found an even higher prevalence of obstruction (25\% of cases).

The prevalence of hernia in our study was $5.3 \%$, with a predominance of umbilical localization in $75 \%$ of cases. Miftah et al. [5], Flayou et al. [7], Villemain et 
al. in France [9] and Huraib et al. [8] found a higher prevalence at 21.7\%, 12.2\%, $11.8 \%$ and $10 \%$, respectively. In PD this complication generally constitutes the recurrence of a pre-existing hernia and the number increases with age [9] [10]. In our series, patients who presented with hernia had a relatively low average age, lower than that of the other series. Furthermore, none had a history of hernia, hence this lower frequency.

Accidental cutting was found in $8 \%$ of our patients. This mechanical complication had the longest average time to onset (13.5 \pm 8.9 months).

Miftah et al. [5] found a slightly lower prevalence at $6.5 \%$ after a long average delay (25.6 months). Flayou et al. [7] and Raina et al. in India [11] found a much lower prevalence of $3.4 \%$ and $2.47 \%$, respectively. This difference in prevalence could be explained by the fact that some of the teams put the catheter in pockets that the patient carried regularly, which made it possible to protect the catheter. The other complicating factors related to the age of the catheter, the use of sharp clamps, the repeated use of disinfectants and the use of radio opaque barium sulphate catheters.

One patient presented with an intestinal perforation. Asif et al. in the USA [12] and Peppelenbosh et al. in Holland [13] found a prevalence of $0.8 \%$ and $0.9 \%$, respectively.

Intestinal perforation is an infrequent but serious complication associated with significant morbidity and mortality [14]. One of the risk factors is the presence of intestinal distension, hence the value of preoperative laxatives.

Postoperative wall bleeding and hemoperitoneum were infrequent in our series. These are relatively mild complications that can be avoided by minimally invasive techniques for implanting the dialysis catheter [15] [16]. Indeed, over a period of 10 years, Vaux et al. [17] did not report any bleeding episodes after insertion of the catheter by the fluoroscopic method.

Regarding metabolic complications, the prevalence of hypokalaemia was 55.9\%. Chuang et al. in Taiwan [18] noted a similar prevalence (56.8\%). Hypokalaemia is a fairly common complication in PD; its prevalence varies between $10 \%$ and $58 \%$ [19] [20] and is probably influenced by differences in dietary potassium intake between countries.

In our study, the average albumin level was $27.3 \pm 4.9 \mathrm{~g} / \mathrm{l}$, compared with 32.3 $\pm 4.3 \mathrm{~g} / \mathrm{l}$ in a series by Kaysen et al. in the USA [21]. These differences can be explained by the overall nutritional status of patients with end-stage CKD in our context. Patients are diagnosed at advanced stages of the disease, often with poor nutritional status. This already precarious state is aggravated when the patient begins peritoneal dialysis, due to peritoneal albumin losses.

The prevalence of hypercholesterolemia was $59.3 \%$ and that of hypertriglyceridemia, $14.8 \%$. The aetiologies of hyperlipidaemia are multifactorial. On the one hand, the significant absorption of glucose from the dialysate constitutes a substrate for the synthesis of lipoprotein, having as a corollary the rise in the plasma lipid level. On the other hand, the increased peritoneal loss of proteins 
(including albumin and other lipoprotein regulating substances) is the cause.

Limitations of our study lie in its retrospective aspect and the usual bias in connection with this type of study.

\section{Conclusion}

In our study, non-infectious complications related to peritoneal dialysis were frequent and varied. They were often the cause of definitive transfer to haemodialysis. The establishment of a therapeutic and dietetic education unit is necessary to reduce the prevalence of these complications.

\section{Acknowledgements}

Our thanks to the entire urology team and the nurses in our PD unit for their involvement in the management of non-infectious PD complications.

\section{Conflicts of Interest}

The authors declare no conflicts of interest regarding the publication of this paper.

\section{References}

[1] Jain, A., Blake, P., Cordy, P., et al. (2012) Global Trends in Rates of Peritoneal Dialysis. Journal of the American Society of Nephrology, 23, 533-544. https://doi.org/10.1681/ASN.2011060607

[2] McCormick, B.B. and Bargman, J.B. (2007) Noninfectious Complications of Peritoneal Dialysis: Implications for Patient and Technique Survival. Journal of the American Society of Nephrology, 18, 3023-3025. https://doi.org/10.1681/ASN.2007070796

[3] Kolesnyk, I., Dekker, F., Boeschoten, E., et al. (2010) Time-Dependent Reasons for Peritoneal Dialysis Technique Failure and Mortality. Peritoneal Dialysis International, 30, 170-177. https://doi.org/10.3747/pdi.2008.00277

[4] Brown, E., Van Biesen, W., Finkelstein, F., et al. (2009) Length of Time on Peritoneal Dialysis and Encapsulating Peritoneal Sclerosis: Position Paper for ISPD. Peritoneal Dialysis International, 29, 595-600. https://doi.org/10.1177/089686080902900602

[5] Miftah, M., Asseban, M., Bezzaz, A., et al. (2014) Mechanical Complications of Peritoneal Dialysis. Open Journal of Nephrology, 4, 103-109.

https://doi.org/10.4236/ojneph.2014.43015

[6] Prakash, J., Singh, S., Shreeniwas, S., et al. (2011) Non-Infectious Complications of Continuous Ambulatory Peritoneal Dialysis and Their Impact on Technique Survival. Indian Journal of Nephrology, 21, 112-115. https://doi.org/10.4103/0971-4065.82125

[7] Flayou, K., Ouzeddoun, N., Bayahia, R., et al. (2016) Mechanical Complications of Continuous Ambulatory Peritoneal Dialysis: Experience at the Ibn Sina University Hospital. Saudi Journal of Kidney Diseases and Transplantation, 27, 107-110. https://doi.org/10.4103/1319-2442.174089

[8] Huraib, S., Abu-Aisha, H., Memon, N., et al. (1995) Non-Peritonitis Complications of Continuous Ambulatory Peritoneal Dialysis in Saudi Arabia. Annals of Saudi 
Medicine, 15, 458-461. https://doi.org/10.5144/0256-4947.1995.458

[9] Villemain, F., Ryckelynck, J., Lobbedez, T., et al. (2002) Complications abdominales en dialyse péritonéale. Néphrologie, 23, 237-243.

[10] Gotloib, L., Mines, M., Garmizo, L., et al. (1981) Hemodynamic Effects of Increasing Intra-Abdominal Pressure in Peritoneal Dialysis. Peritoneal Dialysis International, 1, 41-43. https://doi.org/10.1177/089686088000100406

[11] Raina, A., Saleem, S., Jan, S., et al. (2017) Mechanical Complications of Continuous Ambulatory Peritoneal Dialysis: A Hospital Based Retrospective Study in Kashmir Valley. Archives of Medicine and Health Sciences, 5, 21-23.

[12] Asif, A., Byers, P., Vieira, C., et al. (2003) Peritoneoscopic Placement of Peritoneal Dialysis Catheter and Bowel Perforation: Experience of an Interventional Nephrology Program. American Journal of Kidney Diseases, 42, 1270-1274. https://doi.org/10.1053/j.ajkd.2003.08.029

[13] Peppelenbosch, A., Van Kuijk, W.H.M., et al. (2008) Peritoneal Dialysis Catheter Placement Technique and Complications. NDT Plus, 1, iv23-iv28. https://doi.org/10.1093/ndtplus/sfn120

[14] Wakeen, M., Zimmerman, S. and Bidwell, D. (1994) Viscus Perforation in Peritoneal Dialysis Patients: Diagnosis and Outcome. Peritoneal Dialysis International, 14, 371-377. https://doi.org/10.1177/089686089401400411

[15] Gadallah, M., Pervez, A., el-Shahawy, M., et al. (1999) Peritoneoscopic versus Surgical Placement of Peritoneal Dialysis Catheters: A Prospective Randomized Study on Outcome. American Journal of Kidney Diseases, 33, 118-122. https://doi.org/10.1016/S0272-6386(99)70266-0

[16] Wright, M., Bel'eed, K., Johnson, B., et al. (1999) Randomized Prospective Comparison of Laparoscopic and Open Peritoneal Dialysis Catheter Insertion. Peritoneal Dialysis International, 19, 372-375. https://doi.org/10.1177/089686089901900415

[17] Vaux, E., Torrie, P., Barker, L., et al. (2008) Percutaneous Fluoroscopically Guided Placement of Peritoneal Dialysis Catheters: A 10-Year Experience. Seminars in Dialysis, 21, 459-465. https://doi.org/10.1111/j.1525-139X.2008.00463.x

[18] Chuang, Y., Shu, K., Yu, T., et al. (2009) Hypokalemia: An Independent Risk Factor of Enterobacteria Peritonitis in CAPD Patients. Nephrology Dialysis Transplantation, 24, 1603-1608. https://doi.org/10.1093/ndt/gfn709

[19] Tziviskou, E., Musso, C., Bellizzi, V., et al. (2003) Prevalence and Pathogenesis of Hypokalemia in Patients on Chronic Peritoneal Dialysis: One Center's Experience and Review of the Literature. International Urology and Nephrology, 35, 429-434. https://doi.org/10.1023/B:UROL.0000022867.93739.03

[20] Khan, A., Bernardini, J., Johnston, J., et al. (1996) Hypokalemia in Peritoneal Dialysis Patients. Peritoneal Dialysis International, 16, 652. https://doi.org/10.1177/089686089601600628

[21] Kaysen, G., Rathore, V., Shearer, G., et al. (1995) Mechanisms of Hypoalbuminemia in Hemodialysis Patients. Kidney International, 48, 510-516. https://doi.org/10.1038/ki.1995.321 